\title{
Strategies for immunisation against rubella: evidence from a study in the Kalutara District
}

\author{
P Palihawadana ${ }^{1}$, A R Wickremasinghe ${ }^{2}$ and J Perera ${ }^{3}$ \\ (Index words: Susceptibility to rubella, three immunisation schedules)
}

\begin{abstract}
Objective To simulate different immunisation programs against rubella and estimate the proportion of the population susceptible to rubella infection of each.

Methods The impact of 3 immunisation schedules on the susceptibility of women of childbearing age and the community to rubella infection was simulated using a probabilistic approach. The first schedule involved selective immunisation of 12-year old girls, the second immunisation of all children at 3 years of age for different immunisation coverages, and the third comprised a combination of the first two. The proportion of different segments of the population currently susceptible to rubella was obtained from a field study conducted in the Kalutara District in 1999.
\end{abstract}

Results An immunisation program of 12-year old girls will reduce the susceptibility to rubella in 5 years in only the 15 to 19 year age group. In 10 years, the susceptibility in both the 15 to 19 and 20 to 24 year age groups will be reduced. Immunisation only of children at 3 years will take 20 years for a reduction in the susceptibility to rubella infection in the 15 to 19 year and the 20 to 24 year age groups, and the proportion of the population susceptible to rubella can be reduced to less than $10 \%$ in 20 years if $90 \%$ coverage is attained. If a combination of the two strategies ie. selective immunisation of girls at 12 years for 10 years and immunisation of all children at 3 years is adopted, the proportion of the community susceptible to rubella will be less than $14 \%$ in 10 years.

Conclusions The combination of immunising girls at 12 years of age for 10 years and all children at 3 years of age against rubella is recommended for Sri Lanka to reduce the risk of congenital rubella syndrome in the short term and the proportion susceptible to rubella in the community in the long term.

\section{Introduction}

Epidemics of rubella have occurred in many countries and in Sri Lanka in the 1990s (1,2,3). In some districts of Sri Lanka, $43 \%$ of women in the childbearing age were found to be susceptible to rubella infection (4), a proportion higher than in most temperate countries (5). More than 70 high and middle income countries have introduced rubella vaccines in their national programs.
Based on available infomation on rubella infection and congenital rubella syndrome (CRS), the National Advisory Committee on Communicable Diseases of Sri Lanka decided to introduce rubella vaccine into the routine immunisation program. Initially the target groups for immunisation were 11 to 15 year old schoolgirls and women between 16 and 44 years. From year 2001 children 3 years of age are also immunised against rubella. This immunisation strategy is aimed at reducing the number of susceptible women during pregnancy, and in the community, with the ultimate aim of elimination of CRS and interruption of transmission.

The purpose of our study was to simulate outcomes for different immunisation strategies against rubella to estimate the proportion susceptible to rubella infection.

\section{Materials and Methods \\ Simulation studies}

a) Impact on women of childbearing age

We simulated the impact of different immunisation schedules on the susceptibility of women of childbearing age to rubella infection using a probabilistic approach. Two simulations were performed; the first involved selective immunisation of 12-year old girls (strategy 1 ) and the second involved selective immunisation of all children at 3 years of age (strategy 2) for different immunisation coverages. The proportion of different segments of the population currently susceptible to rubella was obtained from a field study conducted in the Kalutara District in 1999 (6). It was assumed that the immunisation is $100 \%$ effective and that immunity is lifelong. The expected reduction in the proportion of women of childbearing age susceptible to rubella for a specific age group was derived by multiplying the probability of being currently susceptible to rubella infection by the probability of being immunised under different immunisation stratgies (ie. immunising girls at 12 years of age and immunising all children at 3 years of age for different immunisation coverages). This reduction was estimated for different time periods. A third simulation was done combining the above two strategies (strategy 3) as an extension of the mathematical derivation and assuming the following: 1. an immunisation strategy involving

${ }^{1}$ Epidemiological Unit, Department of Health Services, De Saram Place, Colombo 10; ${ }^{2}$ Department of Community Medicine and Family Medicine, Faculty of Medical Sciences, University of Sri Jayawardenapura, Nugegoda; ${ }^{3}$ Department of Microbiology, Faculty of Medicine, University of Colombo, Colombo 8. (Correspondence: ARN, tel: 01 598014; email: arwicks@sltnet.lk. Submitted 25 September 2001, revised version accepted 15 March 2002). 
concurrent immunisation of 12-year old females and 3-year old children for 10 years followed by immunisation of only 3 -year old children 2. an individual is not immunised twice, and 3 . the immunisation is $100 \%$ effective and lifelong.

\section{b) Impact on the community}

The proportion of the total population susceptible to rubella for different immunisation strategies for selected years was estimated using a similar approach as above. The proportion of the community susceptible to rubella was the sum of the proportions of people susceptible to rubella for different age-sex groups, the proportions being of the community as a whole. The proportion of a particular age-sex group susceptible to rubella was obtained by multiplying the expected proportion of the community for a particular age-sex group for a given year (ie. based on the projected population for Sri Lanka) by the estimated proportion of individuals susceptible to rubella in the same age-sex group for a given immunisation strategy. The proportion of age-sex groups susceptible to rubella was taken from the results of the Kalutara study (6). It was assumed that there are no sex differences in susceptibility to rubella, and that at age 50 years and beyond, only $5 \%$ of the population will be susceptible.

\section{Results}

Table 1 gives the proportion of current susceptibles to rubella based on the Kalutara study (6). Tables 2 and 3 give the susceptibilities of females of 15 to 44 years of age for different immunisation coverages of 12-year old girls and 3-year old children, respectively. An immunisation programe of 12-year old girls will reduce the susceptibility to rubella in 5 years in only the 15 to 19 year age group. In 10 years there will be a reduction in the susceptibility in both the 15 to 19 and 20 to 24 year age groups. In 20 years there will be a reduction in the susceptibility to rubella in all age groups except the over 35-year age group. An immunisation strategy concentrating only on immunisation of children at 3 years will take 20 years for a reduction in the susceptibility to rubella infection in the 15 to 19 years and the 20 to 24 years age groups (Table 3 ). Such an immunisation program will take about 40 years to reduce rubella susceptibility in all age groups of women of childbearing age.

The results of the simulation combining the two immunisation strategies ie, selective immunisation of girls at 12 years for 10 years and immunisation of all children at 3 years of age are given in Table 4 . It will take about 30 years to have an impact on rubella susceptibility in all age groups of women of childbearing age.

Table 4 gives the projected proportions of the population susceptible to rubella in selected years for different immunisation strategies. If selective immunisation of 12-year old girls is done, even after 20 years, in 2020, a substantial proportion of the population (in excess of $25 \%$ ) will still be rubella susceptible even with $90 \%$ coverage, as the males are not being immunised (Table 5). In this strategy even marked fluctuations in coverage will have minimum impact on the proportion of the population susceptible to rubella. When children 3 years of age are immunised the proportion of the population susceptible to rubella can be reduced to less than $10 \%$ in 20 years if $90 \%$ coverage is attained. However, for the strategy to have an impact on CRS, a minimum of 15 to 20 years should elapse. If both of the above strategies are adopted, the proportion of the community susceptible to rubella will be less than $14 \%$ in 10 years. This strategy, in addition to reducing the proportion susceptible to rubella in the community, will also have an impact on susceptibility of women of childbearing age. After 10 years, only immunisation of all children at 3 years will be required, and after a period of 20 years the susceptible porportion of the population will be less than $10 \%$.

Table 1. Susceptibility to rubella (6)

\section{Group}

$$
\begin{aligned}
& \text { Age } \\
& \text { group (years) }
\end{aligned}
$$

\author{
Number sero- \\ positive
}

\author{
Number sero- \\ negative
}

\section{Proportion susceptible}

Children

$\begin{array}{ccccc}1-3 & 266 & 15 & 251 & 0.94 \\ 4-6 & 521 & 44 & 477 & 0.92 \\ 7-9 & 321 & 62 & 259 & 0.81 \\ 10-11 & 142 & 36 & 106 & 0.75\end{array}$

Pregnant women

$\begin{array}{lr}<20 & 65 \\ 20-24 & 145 \\ 25-29 & 202 \\ 30.34 & 143 \\ 35-44 & 65\end{array}$

46
106
160
106
53

$\begin{array}{ll}19 & 0.29 \\ 39 & 0.27 \\ 42 & 0.21 \\ 37 & 0.26 \\ 12 & 0.18\end{array}$


Table 2. Susceptibility to rubella infection in females 15 to 44 years of age for different immunisation coverages of 12-year old girls

\begin{tabular}{|c|c|c|c|c|c|}
\hline \multirow[b]{2}{*}{ Age group } & \multirow{2}{*}{$\begin{array}{l}\text { Immunisation } \\
\text { coverage* }(\%)\end{array}$} & \multirow{2}{*}{$\begin{array}{l}\text { Current } \\
\text { susceptibility }^{\delta}\end{array}$} & \multirow[b]{2}{*}{5 years } & \multicolumn{2}{|c|}{ Susceptibility ${ }^{\delta}$ in } \\
\hline & & & & 10 years & 20 years \\
\hline \multirow[t]{3}{*}{$15-19$} & 50 & 0.290 & 0.145 & 0.145 & 0.145 \\
\hline & 75 & 0.290 & 0.073 & 0.073 & 0.073 \\
\hline & 90 & 0.290 & 0.029 & 0.029 & 0.029 \\
\hline \multirow[t]{3}{*}{$20-24$} & 50 & 0.270 & 0.270 & 0.135 & 0.135 \\
\hline & 75 & 0.270 & 0.270 & 0.068 & 0.068 \\
\hline & 90 & 0.270 & 0.270 & 0.027 & 0.027 \\
\hline \multirow[t]{3}{*}{$25-29$} & 50 & 0.210 & 0.210 & 0.210 & 0.105 \\
\hline & 75 & 0.210 & 0.210 & 0.210 & 0.053 \\
\hline & 90 & 0.210 & 0.210 & 0.210 & 0.021 \\
\hline \multirow[t]{3}{*}{$30-34$} & 50 & 0.260 & 0.260 & 0.260 & 0.105 \\
\hline & 75 & 0.260 & 0.260 & 0.260 & 0.053 \\
\hline & 90 & 0.260 & 0.260 & 0.260 & 0.021 \\
\hline \multirow[t]{3}{*}{$35-44$} & 50 & 0.180 & 0.180 & 0.180 & 0.180 \\
\hline & 75 & 0.180 & 0.180 & 0.180 & 0.180 \\
\hline & 90 & 0.180 & 0.180 & 0.180 & 0.180 \\
\hline
\end{tabular}

* Refers to the immunisation coverage of females at 12 years of age

\# Refers to probability of being susceptible to rubella infection for a particular age group

$\delta$ Refers to the expected proportion of women of chilbearing age susceptible to rubella infection

Table 3. Susceptibility to rubella infection in females 15 to 44 years of age for different immunisation coverages of 3-year old children

\begin{tabular}{|c|c|c|c|c|c|}
\hline \multirow[b]{2}{*}{ Age group } & \multirow{2}{*}{$\begin{array}{l}\text { Immunisation } \\
\text { coverage }^{*}(\%)\end{array}$} & \multirow{2}{*}{$\begin{array}{l}\text { Current } \\
\text { susceptibility }^{\delta}\end{array}$} & \multirow[b]{2}{*}{20 years } & \multicolumn{2}{|c|}{ Susceptibility ${ }^{\delta}$ in } \\
\hline & & & & 30 years & 40 years \\
\hline \multirow[t]{3}{*}{$15-19$} & 50 & 0.290 & 0.145 & 0.145 & 0.145 \\
\hline & 75 & 0.290 & 0.073 & 0.073 & 0.073 \\
\hline & 90 & 0.240 & 0.029 & 0.029 & 0.029 \\
\hline \multirow[t]{3}{*}{$20-24$} & 50 & 0.270 & 0.135 & 0.135 & 0.135 \\
\hline & 75 & 0.270 & 0.068 & 0.068 & 0.068 \\
\hline & 90 & 0.270 & 0.027 & 0.027 & 0.027 \\
\hline \multirow[t]{3}{*}{$25-29$} & 50 & 0.210 & 0.210 & 0.105 & 0.105 \\
\hline & 75 & 0.210 & 0.210 & 0.053 & 0.053 \\
\hline & 90 & 0.210 & 0.210 & 0.021 & 0.021 \\
\hline \multirow[t]{3}{*}{$30-34$} & 50 & 0.260 & 0.260 & 0.105 & 0.105 \\
\hline & 75 & 0.260 & 0.260 & 0.053 & 0.053 \\
\hline & 90 & 0.260 & 0.260 & 0.021 & 0.021 \\
\hline \multirow[t]{3}{*}{$35-44$} & 50 & 0.180 & 0.180 & 0.180 & 0.090 \\
\hline & 75 & 0.180 & 0.180 & 0.180 & 0.045 \\
\hline & 90 & 0.180 & 0.180 & 0.180 & 0.018 \\
\hline
\end{tabular}


Table 4. Susceptibility to rubella infection in females 15 to 44 years of age for different immunisation coverages of 3-year old children and 12-year old girls

\begin{tabular}{|c|c|c|c|c|c|}
\hline \multirow[b]{2}{*}{ Age group } & \multirow{2}{*}{$\begin{array}{l}\text { Immunisation } \\
\left.\text { coverage* }^{*} \%\right)\end{array}$} & \multirow{2}{*}{$\begin{array}{l}\text { Current } \\
\text { susceptibility }^{\delta}\end{array}$} & \multirow[b]{2}{*}{10 years } & \multicolumn{2}{|c|}{ Susceptibility ${ }^{\delta}$ in } \\
\hline & & & & 20 years & 30 years \\
\hline \multirow[t]{3}{*}{ 15-19 } & 50 & 0.290 & 0.145 & 0.145 & 0.145 \\
\hline & 75 & 0.290 & 0.073 & 0.073 & 0.073 \\
\hline & 90 & 0.290 & 0.029 & 0.029 & 0.029 \\
\hline \multirow[t]{3}{*}{$20-24$} & 50 & 0.270 & 0.135 & 0.135 & 0.135 \\
\hline & 75 & 0.270 & 0.068 & 0.068 & 0.068 \\
\hline & 90 & 0.270 & 0.027 & 0.027 & 0.027 \\
\hline \multirow[t]{3}{*}{$25-29$} & 50 & 0.210 & 0.210 & 0.105 & 0.105 \\
\hline & 75 & 0.210 & 0.210 & 0.053 & 0.053 \\
\hline & 90 & 0.210 & 0.210 & 0.021 & 0.021 \\
\hline \multirow[t]{3}{*}{$30-34$} & 50 & 0.260 & 0.260 & 0.105 & 0.105 \\
\hline & 75 & 0.260 & 0.260 & 0.053 & 0.053 \\
\hline & 90 & 0.260 & 0.260 & 0.021 & 0.021 \\
\hline \multirow[t]{3}{*}{$35-44$} & 50 & 0.180 & 0.180 & 0.180 & 0.090 \\
\hline & 75 & 0.180 & 0.180 & 0.180 & 0.045 \\
\hline & 90 & 0.180 & 0.180 & 0.180 & 0.018 \\
\hline
\end{tabular}

\footnotetext{
* Refers to the immunisation coverage of females at 12 years of age and all children at 3 years of age

\# Refers to probability of being susceptible to rubella infection for a particular age group

$\delta$ Refers to the expected proportion of women of chilbearing age susceptible to rubella infection
}

\section{Table 5. Projected proportion of population susceptible to rubella in selected years for different immunisation strategies}

\begin{tabular}{|c|c|c|c|c|}
\hline Strategy & $\begin{array}{c}\text { coverage } \\
(\%)\end{array}$ & 2010 & 2020 & 2030 \\
\hline Selective & 50 & 0.312 & 0.271 & Not done \\
\hline immunisation & 75 & 0.307 & 0.263 & \\
\hline at 12 years & 90 & 0.304 & 0.260 & \\
\hline \multirow{3}{*}{$\begin{array}{l}\text { Immunisation } \\
\text { at } 3 \text { years }\end{array}$} & 50 & Not done & 0.189 & 0.162 \\
\hline & 75 & & 0.138 & 0.109 \\
\hline & 90 & & 0.108 & 0.077 \\
\hline Selective & 50 & 0.217 & 0.180 & Not done \\
\hline immunisation & 75 & 0.164 & 0.126 & \\
\hline $\begin{array}{l}\text { at } 12 \text { years and } \\
\text { all at } 3 \text { years }\end{array}$ & 90 & 0.132 & 0.094 & \\
\hline
\end{tabular}

\section{Discussion}

Studies of the transmission dynamics of rubella virus have stressed the importance of quantitative information concerning age specific rates of infection to any detailed assessment of the impact of immunisation on the incidence of rubella and CRS $(8,9)$. Advances in the development of a mathematical framework to aid in the design of immunisation programs have, to some extent, outstripped the acquisition of relevant epidemiological data needed to compare predictions with observation. The combination of these theoretical and empirical components is required to assess the likely impact of different immunisation policies.

The impact of various vaccination policies on the incidence of CRS in the United Kingdom with a mathematical model of the transmission dynamics of the rubella virus suggest that to reduce the incidence of CRS in the future years would require high rates of vaccination of both girls 
and boys of about two years of age (9). Minor epidemics that may appear every 20 to 22 years do not indicate a failure in this policy, which is more beneficial than continuing a selective strategy of immunisation $(9,10,11)$. A selective vaccination policy does not aim to eliminate virus transmission in the community, and outbreaks of rubella will occur, with rubella susceptible people being infected, including pregnant women (12). The selective rubella immunisation policy practised earlier in Sri Lanka, vaccinating only women of childbearing ages of 11 to 44, had little impact on virus transmission within the younger segments of the population.

The first strategy simulated in our study aims at reducing the risk of CRS. In this strategy, it will take at least 10 years to have an impact on the 20-24 year old group, and 20 years on all females below 35 years of age. Although the proportion of women between 15 to 35 years susceptible to rubella can be reduced to 2 to $3 \%$ in 20 years, $26 \%$ of the community will still be susceptible in 20 years even with $90 \%$ coverage. Although this approach will decrease the risk of CRS, a proportion of the population will still be susceptible to rubella and may trigger epidemics. Even the 2 to $3 \%$ of susceptible females between 15 to 35 years will not be immune to the risk of CRS.

The second strategy, which aims to reduce the proportion of the population susceptible to rubella, is primarily targeted at reducing the possibility of the occurrence of rubella epidemics. For this strategy to have a significant impact by itself on women 15 to 35 years of age would take at least 40 years. However, the impact on the community with $90 \%$ coverage will be substantial with only $10 \%$ of the population being susceptible in 20 years.

The third strategy is a combination of the two. Selective immunisation of girls at 12 years of age has to be done only for 10 years, as after that children immunised at 3 years will constitute the cohort at 12 years. It aims at reducing the susceptibility to rubella of both women of childbearing age and the community as a whole in a short time. In 20 years an effect will be seen in women 15 to 35 years of age. With $90 \%$ coverage of both immunisation schedules the proportion of the population susceptible to rubella can be decreased to less than $10 \%$ in 20 years. This may be sufficient to eliminate rubella transmission in the community, and hence, the occurrence of CRS.

The decision to start a vaccination policy against rubella needs careful local epidemiological studies (13). The median age of rubella infection in Sri Lanka is about 25 years (6). Given this high median age it is imperative that any vaccination strategy should focus on reducing the number of women in the childbearing ages susceptible to rubella in the short term.

Even with individual follow up of non-immune women, total vaccination of the target group cannot be achieved (14). The risk of infection among the remaining susceptible population is directly dependent on the prevalence of rubella, particularly among children. As only $25 \%$ of children are immune to rubella at 11 years of age in Sri Lanka (6), the selective vaccination of women of childbearing age must be augmented by additional rubella vaccination of children of both sexes to eliminate CRS. This two- pronged approach is recommended, ie. vaccination of girls at 12 years of age and all children at 3 years. Vaccination of 12-year old girls should be continued for ten years. An alternative to the two-pronged approach would be to have a "pulse rubella" strategy for all children less than 3 years of age. This would eliminate the need for having two target groups for immunisation and may be more operationally feasible in the long term. A supplement to this strategy would be the incorporation of a "pulse rubella" strategy of all women of childbearing age to be conducted within a year, to reduce the number of currently rubella susceptible women in the reproductive years.

Although our findings are extrapolations derived from one area of Sri Lanka, the implications of different polices can be evaluated. The estimates obtained are comparable with those of other countries, which have a long history of rubella immunisation. For example, in the USA, it has taken almost 30 years since the licensure of the vaccine to reduce the susceptible population to less than $5 \%$. Although the recommendations made in our study may appear clear-cut in the light of data available (6) and the analyses employed, some important caveats need emphasis. Firstly, the conclusions are based only on the predictions of a mathematical model. The actual transmission dynamics of viral infections within human communities are difficult to predict. Secondly, unless the vaccination coverage of 3-year old children reaches high levels there is little advantage to be gained from adopting the twopronged immunisation strategy.

\section{Acknowledgements}

We acknowledge the technical support given by the Dr W S Jayakuru, former Epidemiologist, Epidemiological Unit and the staff of the Epidemiological Unit, and the Department of Microbiology, Faculty of Medicine, University of Colombo. We also thank Dr K A P Gnanissara, and the Deputy Provincial Director of Health Services, Kalutara, and his staff for assisting in the community survey.

\section{References}

1. Robertson SE, Cutts FT, Samuel R, Diaz Ortega JL. Control of rubella and congenital syndrome (CRS) in developing countries, Part 2- Vaccination against rubella. Bulletin of the World Health Organization 1997; 75: 69-80.

2. Basu RN. Rubella and congenital rubella syndrome status and control of programme in South East Asia region. South East Asia Regional Report, World Health Organization, July-August, 1996: 1-11.

3. World Health Organization. Expanded Programme on Immunization. Rubella outbreak, Oman. Weekly Epidemiological Record 1994: 69: 333-6.

4. Mendis L. Susceptibility to rubella virus among Sri Lankan women. Ceylon Medical Journal 1989; 34: 73-5.

5. Cutts FT, Robertson SE, Ortega JLD, Samuel R. Control of rubella and congenital rubella syndrome in developing countries, Part1 - Burden of disease from CRS. Bulletin of the World Health Organization 1997; 75: 55-68. 
6. Palihawadana P. A study of rubella infection among children in the community and factors associated with susceptibility to rubella during pregnancy. M.D. Thesis, University of Colombo, Sri Lanka, 2000.

7. Abeykoon ATPL. Population and manpower resources of Sri Lanka. Natural Resources, Energy and Science Authority of Sri Lanka, 1998.

8. Anderson RM, May RM. Vaccination against rubella and measles: quantitative investigation of different policies. Journal of Hygiene 1983; 90: 259-325.

9. Anderson RM, Grenfell BT. Quantitative investigations of different vaccination policies of the control of congenital rubella syndrome (CRS) in the United Kingdom. Journal of Hygiene, 1986; 96: 305-33.
10. Knox EG. Strategy for rubella vaccination. International Journal of Epidemiology 1980; 9: 13-23.

11. Knox EG. Evolution of rubella vaccine policy for the UK. International Journal of Epidemiology 1987; 16: 569-78.

12. Best J, Baker DA, Welch JM, Banatvala JE. Maternal rubella at St. Thomas Hospital in 1978 and 1986. Support for augmenting the rubella vaccination programe. Lancet 1987; ii: 88-90.

13. Hizel S. When should rubella immunisation be introduced? Postgraduate Doctor Middle East 1995; 18: 273-6.

14. Miller CL, Miller E, Waight PA. Rubella susceptibility and the continuing risk of infection in pregnancy. British Medical Journal 1987; 291: 1308-401.

\section{Confidential plan to "shape" medical opinion}

A confidential draft document leaked from a medical communication company, In Vivo Communications, describes a three year "medical education programme" to create a new perception of irritable bowel syndrome as a "credible, common and concrete disease." The proposed 2001-3 education programme is part of the marketing strategy for GlaxoSmithKline's drug Lotronex (alosetron hydrochloride).

In Vivo is one of handful of companies specialising in corporate backed "medical education", and the leaked plan provides a rare insight into the highly secretive world of drug promotion, with its new emphasis on "shaping" medical and public opinion about the latest diseases.

Moynihan R, Heath I, Henry D. Selling sickness: the pharmaceutical industry and disease mongering. BMJ 2002; 324: 887. 